\title{
EFFECTS OF HUSK, COB AND PERICARP CHARACTERISTICS ON KERNEL MOISTURE CONTENT IN CORN DURING THE GRAIN-FILLING STAGE
}

\author{
Lingyan Dai ${ }^{1 *}$, Xinran Cheng ${ }^{1}$, Yanheng Chen ${ }^{1}$, Jiangshuai Niu ${ }^{1}$, Xinyue Cai ${ }^{1}$, Yutao Liu ${ }^{2}$, Kuide Yin ${ }^{1}$, \\ Haiwang Yue ${ }^{3}$, Shuquan Zhang ${ }^{4}$, Wenhua $\mathrm{Li}^{5}$ \\ ${ }^{1}$ College of Life Science and Technology, Heilongjiang Bayi Agricultural University, Daqing 163319, China; \\ ${ }^{2}$ Qiqihar Branch of Heilongjiang Academy of Agricultural Sciences, Qiqihar 161006, China; \\ ${ }^{3}$ Dryland Farming Institute, Hebei Academy of Agriculture and Forestry Sciences, Hengshui 053000, China/Hebei \\ Provincial Key Laboratory of Crops Drought Resistance Research, Hengshui 053000, China; \\ ${ }^{4}$ Institute of Economic Crops, Heilongjiang Academy of Agricultural Sciences, Harbin 150086, China; \\ ${ }^{5}$ Heilongjiang Academy of Agricultural Sciences, Harbin 150086, China
}

http://doi.org/10.35410/IJAEB.2019.4461

\begin{abstract}
The moisture content in kernels at the time of corn harvest is a key factor affecting the quality, safe storage and economic benefits of mechanized-harvest kernels. To study the unique agronomic traits possessed in husk, cob, and pericarp in corn varieties with a low kernel moisture content at harvest, two corn varieties, Zhengdan 958 and Xianyu 335, that have different dehydration characteristics were used as test materials in this project. The effects of husk, cob and pericarp on kernel moisture content during the grain-filling process were studied in the planting area of Heilongjiang province in Northeast China. The results showed that husk moisture content, cob moisture content, and ears shank length each had an extremely significantly positive correlation with kernel moisture content $(\mathrm{P}<0.01)$; pericarp thickness had a significantly positive correlation with kernel moisture content $(\mathrm{P}<0.05)$; and stomatal perimeter had a negative correlation with kernel moisture content. During the grain-filling stage, Xianyu 335 , which has a low kernel moisture content at harvest, has a low moisture content in husk and cob, long ears shank, large stomata perimeter in the husk, and thin pericarp at the late grainfilling stage. Ears shank length, husk stomatal morphology and pericarp thickness could also be used as reference indices in the selection and breeding of corn varieties with fast kernel dehydration and low moisture content during corn maturation and harvest.
\end{abstract}

Keywords: corn, husk, cob, pericarp, kernel, moisture content.

\section{INTRODUCTION}

Corn is an important food, feed and economic crop in the world and has a crucial position in agricultural production and national economic development. At present, with the limitations on increasing arable land, increasing the yield and quality of corn is a main goal of production. One of the main factors affecting corn quality is the moisture content in corn kernels at the time of harvest, which greatly affects corn-harvesting mechanization, kernel drying, storage, and off-site transportation as well as processing and utilization. Excessive moisture content can cause losses and reduced economic benefits for corn growers and operators (Baute et al, 2002); it can also cause moldy kernels and affect corn quality. 


\section{International Journal of Agriculture, Environment and Bioresearch}

Vol. 4, No. 06; 2019

ISSN: 2456-8643

A previous study showed that eco-meteorological factors, field cultivation management practices during the late corn growth period, and varietal differences can each impact kernel moisture content (Wang and $\mathrm{Li}$, 2017). In a specific planting area, the choice of variety is particularly crucial when the corresponding cultivation management measures are determined. Kernel moisture content is significantly different among varieties, and this trait is heritable (Crane, 1959; Purdy and Crane, 1967). The dehydration rate is related to many agronomic traits such as characteristics of the husk, cob, and kernels as well as ear size. However, most of the related studies were conducted in the mid and late 1900s; there exist few studies in recent years on the agronomic traits that affect the moisture content in corn kernels. Therefore, to study the unique agronomic traits of the husk, cob, and pericarp in corn varieties with a low kernel moisture content at harvest, we used two corn varieties, Zhengdan 958 and Xianyu 335, that have different dehydration characteristics. We studied the effects of agronomic traits such as the husk, cob and kernel pericarp on kernel moisture content during the grain-filling process in a planting area of Heilongjiang province in northeast China. This study will provide a theoretical basis for the selection and breeding of rapid-dehydration corn varieties while laying the foundation for the in-depth study of the kernel dehydration mechanism in corn.

\section{MATERIALS AND METHODS}

\section{Varieties}

Xianyu 335 and Zhengdan 958 were provided by the Qiqihar Branch of Heilongjiang Academy of Agricultural Sciences, China. Zhengdan 958 has dominated during the past 10 years due to its high planting-density tolerance, high yield, comprehensive resistance, and strong adaptability, and it is the corn variety with the largest planting area in China. However, its grainfilling period is lengthy, and its dehydration is slow. In contrast, Xianyu 335 has a fast rate of grain filling and dehydration, and it has the largest planting area in Heilongjiang Province.

\section{Description of the study field}

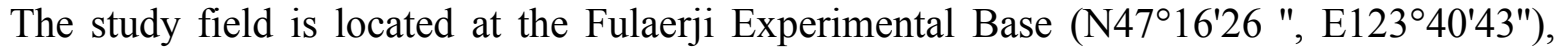
Qiqihar Branch of Heilongjiang Academy of Agricultural Sciences, China. It is at an elevation of $141 \mathrm{~m}$ and has a flat terrain; it is of the carbonate chernozem soil type. The soil fertility in the study area was as follows: $100 \mathrm{mg} \cdot \mathrm{kg}^{-1}$ alkali-hydrolyzable nitrogen, $16.9 \mathrm{mg} \cdot \mathrm{kg}^{-1}$ available phosphorus, $134 \mathrm{mg} \cdot \mathrm{kg}^{-1}$ available potassium, $26.5 \mathrm{~g} \cdot \mathrm{kg}^{-1}$ organic matter, $0.162 \%$ total nitrogen, $0.09 \%$ total phosphorus, $0.5 \%$ total potassium, $0.027 \%$ total salt and a $\mathrm{pH}$ of 7.82 .

\section{Experimental design}

A randomized block design was used in this experiment, with three replicates included. In each plot, 10 rows of plants were included, with the row length being $5 \mathrm{~m}$ long and the row spacing being $0.65 \mathrm{~m}$; each plot had an area of $32.5 \mathrm{~m}^{2}$. Around the experiment fields, four rows of plants were grown as protection rows, respectively. The planting density of the two varieties was 60000 plants $/ \mathrm{hm}^{2}$, and kernel sowing was conducted strictly according to the density ropes (lines) and was carried out on May 8. Fertilizer was applied at an application rate of $25 \mathrm{~kg} / \mathrm{mu}$ (with the N, P and K content each accounting for 15\%) and at $5 \mathrm{~cm}$ below the kernels. Sprinkler irrigation was applied on May 10 with a self-propelled sprinkler irrigation system, with the irrigation amount being $25 \mathrm{~mm}$. Manual weeding was conducted at the 3-leaf stage of corn, 


\section{International Journal of Agriculture, Environment and Bioresearch}

Vol. 4, No. 06; 2019

ISSN: $2456-8643$

followed by the final singling of seedlings. Then, the first round of soil turning and weeding was performed on June 7; next, topdressing was applied (20 kg/mu urea) at the jointing stage, and finally, there was the second round of soil turning and weeding.

\section{Measurements and methods}

In the silking period of corn, corn ears that had robust and uniform growth and had pollen shedding the same day were selected and tagged with labels. After pollination, sampling was performed every $10 \mathrm{~d}$ for a total of 6 times. In the sampling, five ears were sampled for each plot, and for each ear, the length of the ears shank was measured after the removal of the husk.

\section{Determination of moisture content}

The kernel sample included 100 kernels sampled from the middle of each corn ear; the husk sample included all the husks for each corn ear; and the cob sample included the remaining part of the corn ear after the husks and kernels were removed. All the samples were first weighed to obtain their fresh weights, and they were then subjected to fixation at $105{ }^{\circ} \mathrm{C}$ for $30 \mathrm{~min}$. Next, they were oven dried at $80{ }^{\circ} \mathrm{C}$ to their respective constant weights, and finally, they were weighed to obtain their respective dry weights. The moisture content $(\%)$ was calculated as [(fresh weight - dry weight $) /$ fresh weight $] \times 100$, where the fresh weight and dry weight were in grams.

\section{Microscopic observation of kernel pericarp}

The kernels in the middle of the ear were sampled, and for each kernel, the cross-section near the kernel crown was sampled with a sharp blade and was then directly placed on a slide for observation and photographing under a microscope.

\section{Scanning electron microscopic observation of the husk}

Samples were taken from the middle of the innermost husk with a sharp blade, with the sample area being approximately $5 \mathrm{~mm} \times 5 \mathrm{~mm}$. The sample was immediately placed into a glutaraldehyde fixative solution $(\mathrm{pH} 6.7,2.5 \%)$ and was then precipitated by vacuuming with a vacuum pump. After being fixed for $48 \mathrm{~h}$, the sample was first washed three times with PBS solution $\left(0.1 \mathrm{~mol} \cdot \mathrm{L}^{-1}\right)$ and was then subjected to a dehydration series with $50 \%, 70 \%, 90 \%$, and $100 \%$ alcohol, followed by freeze-drying in a tert-butanol solution. Next, the sample was fixed with conductive tape and gold-coated using an ion sputter coater instrument (E-1010, HITACHI, Japan). Last, the sample was photographed under an S-3400N scanning electron microscope.

\section{Data Analysis}

Excel 2007 was used for data processing and graphing, and SPSS 16.0 was used for significance and correlation analysis. One-way analysis of variance (ANOVA) and Duncan's new multiple range test (MRT) were used to compare the significance of differences between varieties.

\section{RESULTS}

Moisture content in kernels, husk and cob 


\section{International Journal of Agriculture, Environment and Bioresearch}

Vol. 4, No. 06; 2019

ISSN: $2456-8643$

The dynamic changes of moisture content in kernels, husk, and cob in the two varieties during the grain-filling stage are shown in Figure 1. After pollination, the kernel moisture contents in the two varieties gradually decreased; at $10 \mathrm{~d}$, no significant difference existed in the kernel moisture content between the two varieties. During the period of $20 \sim 60 \mathrm{~d}$, the kernel moisture contents in Xianyu 335 were all significantly lower than those in Zhengdan 958 $(P<0.05)$ (Figure 1a). Additionally, the husk moisture contents in the two varieties had a gradually decreasing trend. Within $30 \mathrm{~d}$, no significant difference existed in the husk moisture content between the two varieties; during the period of $40 \sim 60 \mathrm{~d}$, the husk moisture contents in Xianyu 335 were all significantly lower than those in Zhengdan $958(P<0.05)$. The husk moisture content in Xianyu 335 was almost unchanged during the period of 20 30d, while that in Zhengdan 958 had little change during the period of 20 40 d (Figure 1b). Furthermore, the cob moisture content in the two varieties also had a decreasing trend. Except for at $10 \mathrm{~d}$, the cob moisture contents at the other times in Xianyu 335 were all significantly lower than those in Zhengdan $958(P<0.05)$. Generally, the cob moisture content was divided into three periods: the first $20 \mathrm{~d}$, during which the moisture content had great changes; the period from 30 40 d, during which the moisture content declined at $30 \mathrm{~d}$, followed by maintaining a level with no significant change unto $40 \mathrm{~d}$; and the period from 50-60 d, during which the cob moisture content was first decreased and was then almost unchanged (Figure 1c).
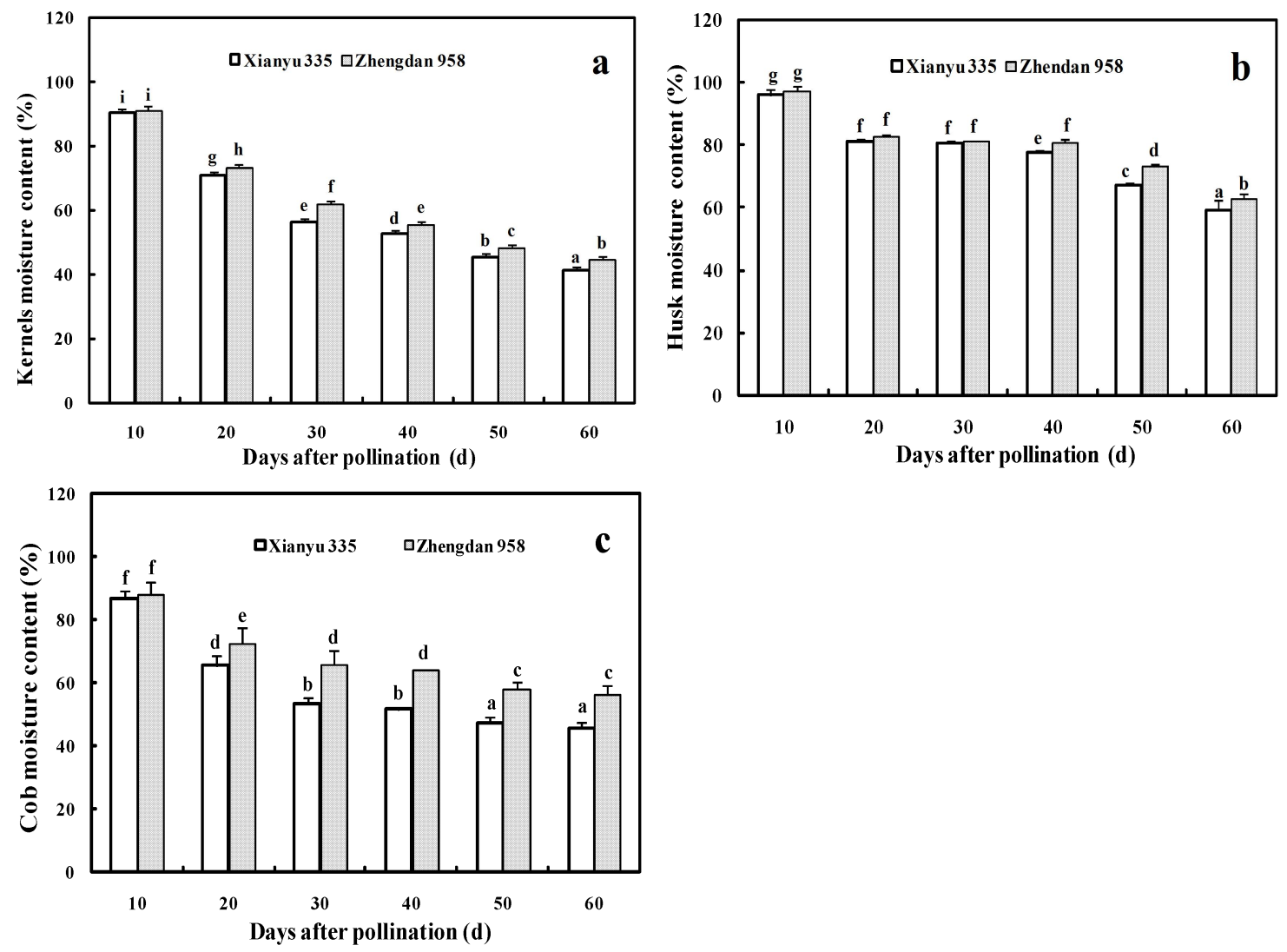

Figure 1 - Dynamic moisture content changes in the kernels, husk and cob of two varieties during the grain-filling stage

Note: Here and below, different letters labeled in the figure indicate difference at the 0.05 significance level. 
Vol. 4, No. 06; 2019

ISSN: $2456-8643$

\section{Ears shank length}

The dynamic changes of the ears shank length in two varieties during the grain-filling stage are shown in Figure 2. The length of ears shank increased gradually. The ears shank length in Xianyu 335 was significantly longer than that in Zhengdan 958 at various sampling times $(P<0.05)$ except for at $10 \mathrm{~d}$.

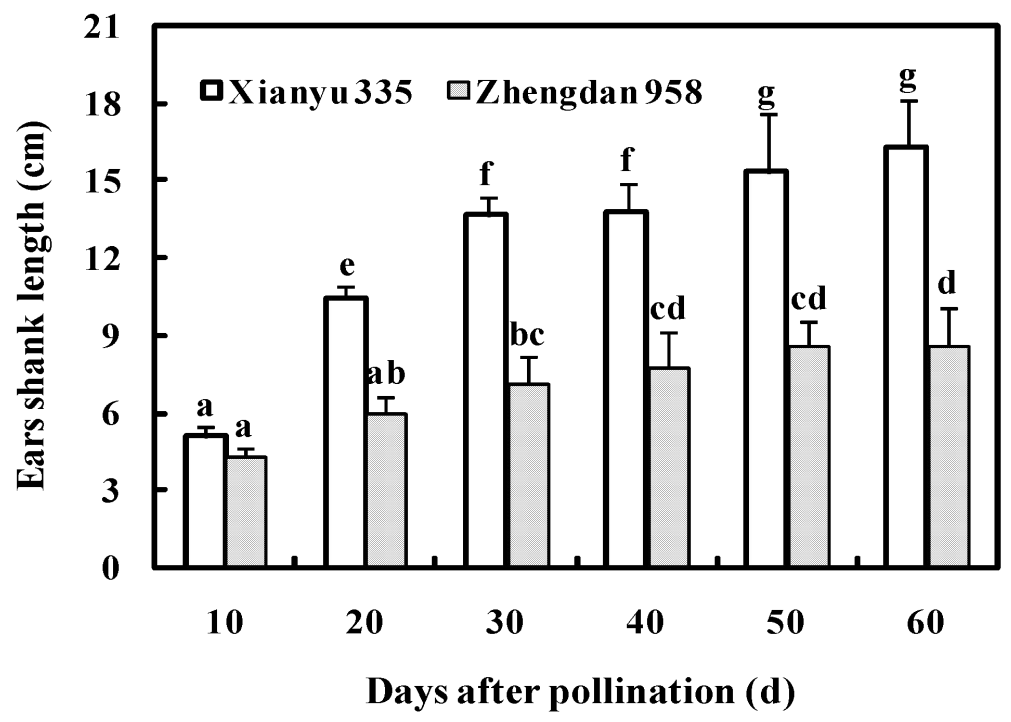

Figure 2 - Dynamic changes in the ears shank length in two varieties during the grain-filling stage

\section{Kernel microscopic observation and pericarp thickness}

The microscopic observation results of Xianyu 335 during the grain-filling stage are shown in Figure 3. At $10 \mathrm{~d}$ after pollination, the ovary wall was relatively thick, and the color in the middle part was darker than that at the two sides. The inner integument was relatively thin, and the interface between the outside ovary wall and the inside endosperm was obvious. At $20 \mathrm{~d}$ after pollination, the ovary wall became thinner, and the integumentary tapetum was concentrated into a black band to connect the ovary wall and the endosperm. The endosperm volume became larger, and the moisture content was relatively large. At $30 \mathrm{~d}$ after pollination, the tapetum disappeared and was fused with the ovary wall into the pericarp, becoming thicker than before; the contents in the endosperm increased, and the moisture content decreased. At $40 \mathrm{~d}$ after pollination, the pericarp became thinner and had a dark color. At 50-60 d after pollination, the pericarp became even thinner, the starch in the endosperm accumulated, and the moisture content decreased. In addition, the dynamic changes in pericarp thickness during the grain-filling stage in the two varieties are shown in Figure 4. The two varieties had a consistent changing trend in pericarp thickness, in that pericarp thickness was the largest at $10 \mathrm{~d}$ after pollination, declined sharply at $20 \mathrm{~d}$, increased at $30 \mathrm{~d}$, and then gradually decreased at $40 \mathrm{~d}$, followed by a gradual trend to approach equilibrium thereafter. The pericarp thickness of Xianyu 335 was significantly higher than that of Zhengdan $958(P<0.05)$ at $10 \mathrm{~d}$, but it was significantly lower than that of Zhengdan $958(P<0.05)$ at $20 \mathrm{~d}$. No significant difference existed between the two varieties in the other periods, but Xianyu 335 had a lower pericarp thickness than Zhengdan 958 during the period from $40 \sim 60 \mathrm{~d}$. 


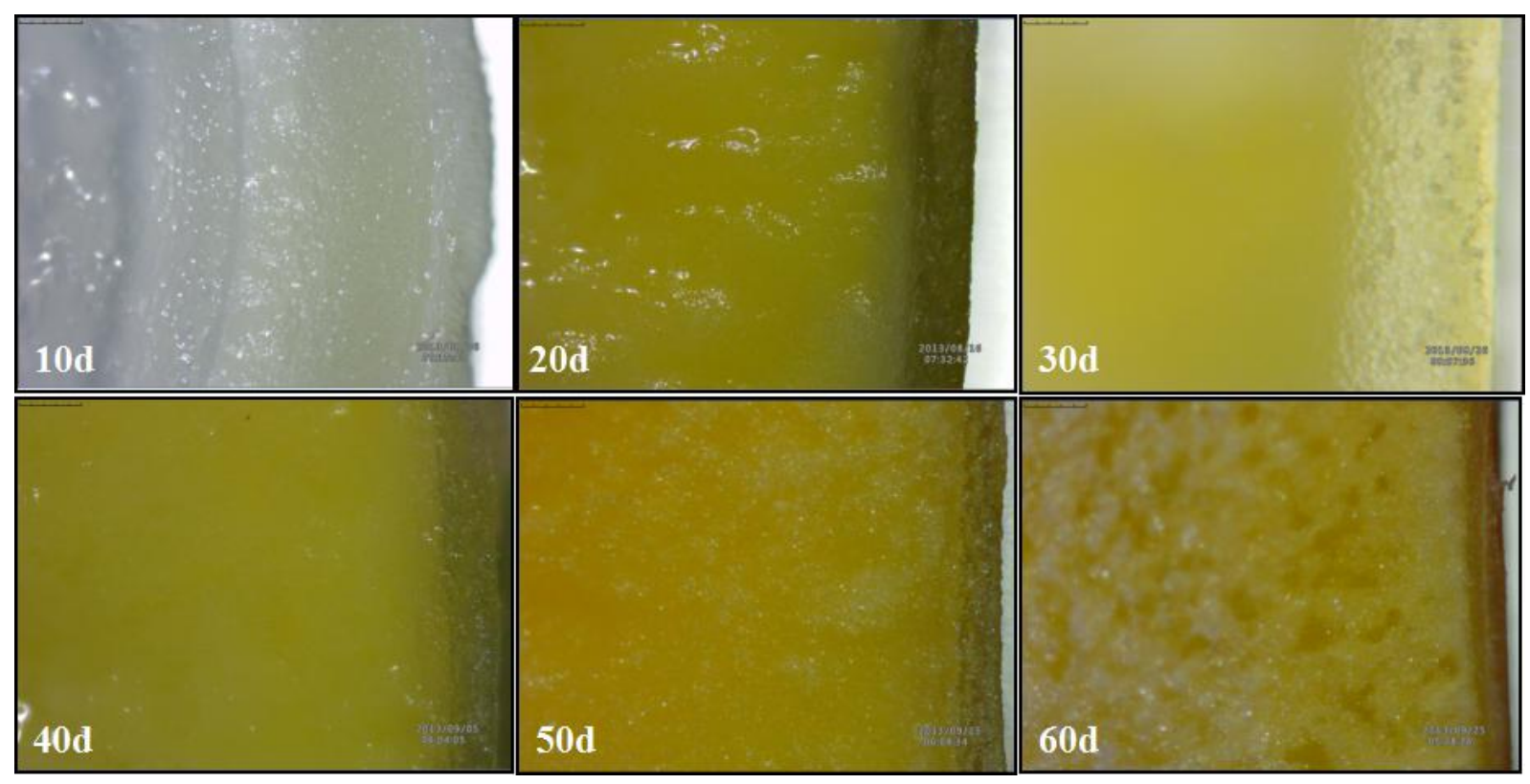

Figure 3 - Microscopic observation of Xianyu 335 during the grain-filling stage

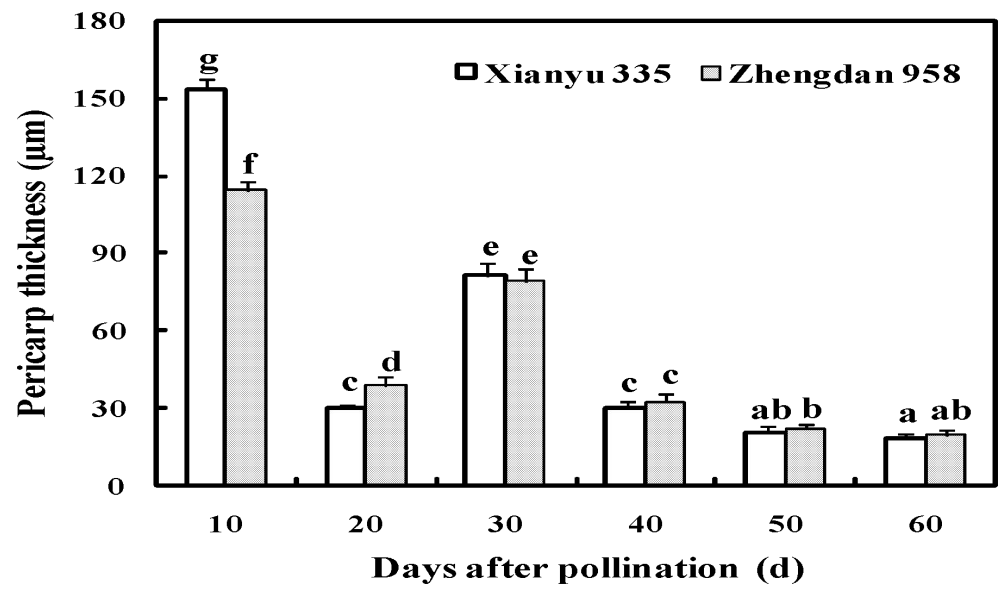

Figure 4 - Dynamic changes in pericarp thickness in two varieties during the grain-filling stage

\section{Scanning electron microscopy observation of husks}

The results of scanning electron microscopy observation of the two varieties' husks at $10 \mathrm{~d}$ after pollination are shown in Figure 5. On the corn husk exist epidermal trichomes with various lengths, above which abundant stomata are distributed. The dynamic changes of stomatal morphology at $20 \mathrm{~d}, 40 \mathrm{~d}$ and $60 \mathrm{~d}$ after pollination in the two varieties are shown in Figure 6. It can be seen from the figure that the stomata of Xianyu 335 were narrow and long at $20 \mathrm{~d}$ and 40 $\mathrm{d}$, while those of Zhengdan 958 were short and ovular; such a pattern can also be clearly seen at $10 \mathrm{~d}$ (Figure 5). At $60 \mathrm{~d}$, the stomata of Xianyu 335 also became short and ovular following the stomata morphology of Zhengdan 958. The dynamic changes of stomatal size within $60 \mathrm{~d}$ after pollination in the two varieties are shown in Table 1 . At $10 \mathrm{~d}$, the radii of the long axis and short 


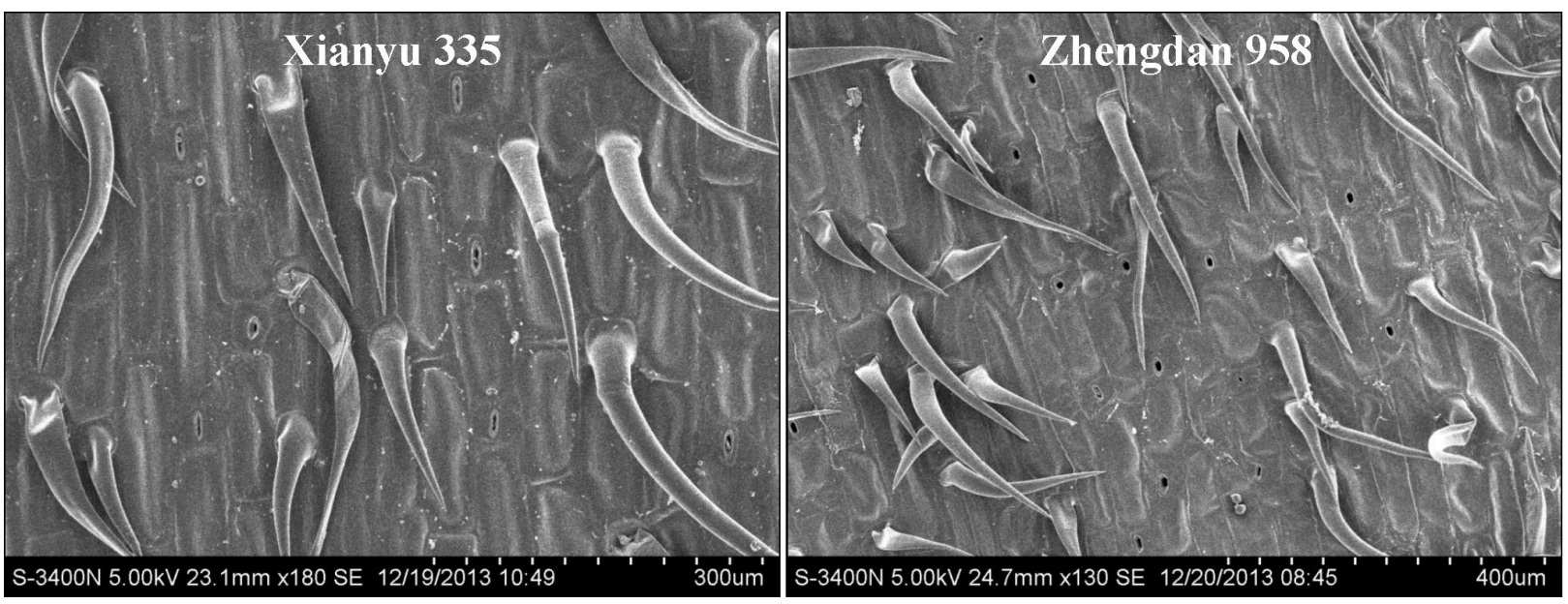

Figure 5 - Scanning electron microscopic observation of husks in two varieties at $10 \mathrm{~d}$ after pollination

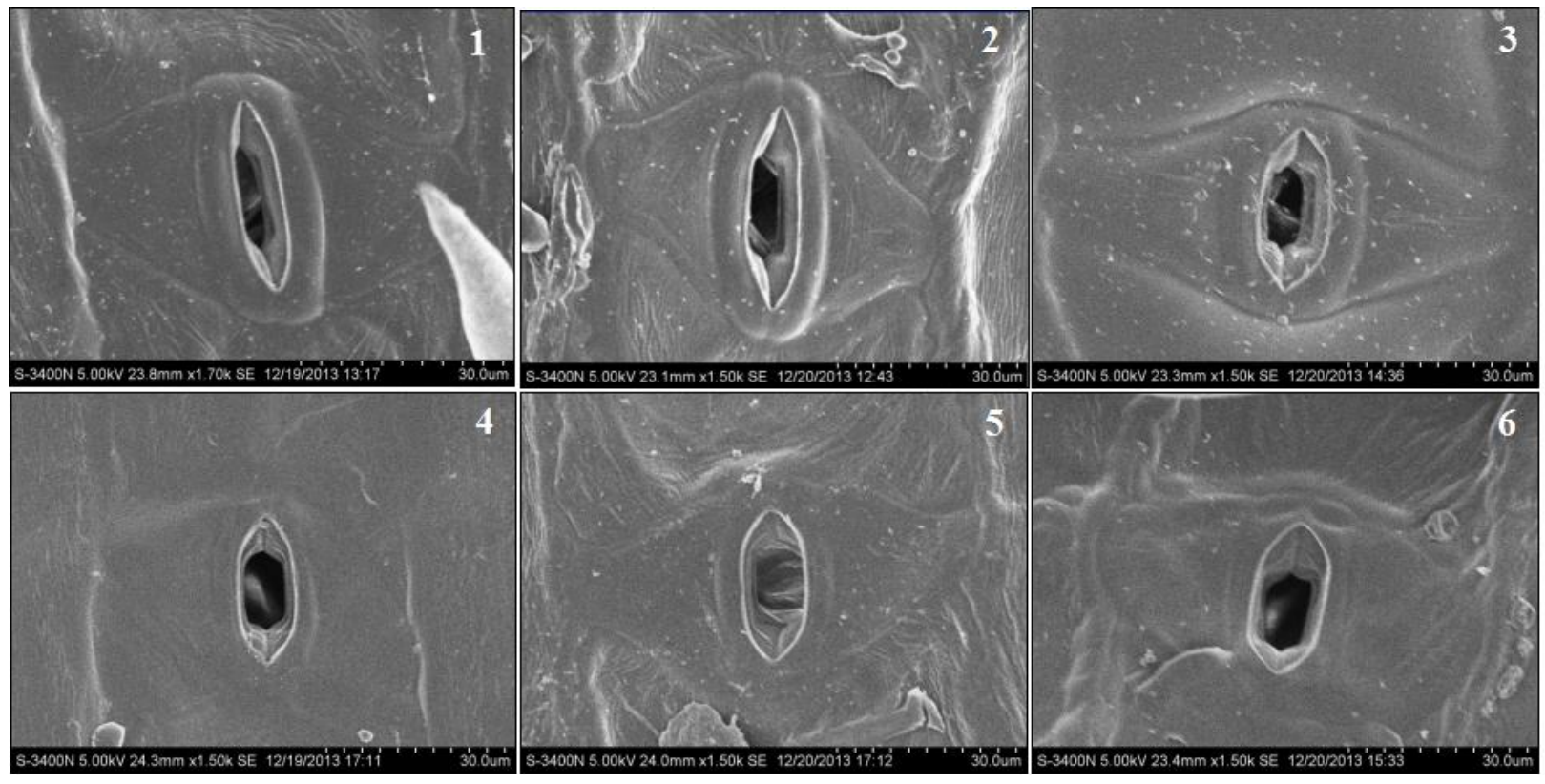

Figure 6 - Dynamic changes in stomatal morphology in two varieties at $20 \mathrm{~d}, 40 \mathrm{~d}$ and $60 \mathrm{~d}$ after pollination

Note: 1, 2 and 3 represent Xianyu 335; 4, 5 and 6 represent Zhengdan 958; 1 and 4 represent $20 \mathrm{~d}$ after pollination; 2 and 5 represent $40 \mathrm{~d}$ after pollination; and 3 and 6 represent $60 \mathrm{~d}$ after pollination.

axis of the stomata in Xianyu 335 were relatively large, and the radius of the long axis and the perimeter in Xianyu 335 were significantly larger than those in Zhengdan $958(P<0.01)$. At $20 \mathrm{~d}$, the radius of the long axis and short axis of the stomata in Zhengdan 958 was increased, but the long axis radius was still significantly smaller than that of Xianyu $335(P<0.05)$. At $30 \mathrm{~d}$, the radius of the long axis of the stomata in Xianyu 335 was the largest during the entire grain-filling 
period, while the radius of the short axis was the smallest; the radius of the long axis of the stomata in Xianyu 335 was significantly larger than that in Zhengdan 958, and the radius of the short axis was significantly smaller $(P<0.05)$. At $40 \mathrm{~d}$, the radius of the short axis of the stomata in Zhengdan 958 was significantly greater than that in Xianyu $335(P<0.01)$. At $60 \mathrm{~d}$, both varieties had the largest radius of the short axis during the entire grain-filling period. With the exception of $50 \mathrm{~d}$, Xianyu 335 had greater stomatal perimeters than Zhengdan 958 at the other periods.

Table 1 - Dynamic changes of stomatal size in two varieties at $60 \mathrm{~d}$ after pollination (unit: $\mu \mathrm{m}$ )

\begin{tabular}{cccc|lccc}
\hline & \multicolumn{3}{c|}{ Xianyu 335 } & \multicolumn{3}{c}{ Zhengdan 958 } \\
\cline { 2 - 8 } Varieties & $\begin{array}{l}\text { Long axis } \\
\text { radius }\end{array}$ & $\begin{array}{l}\text { Short axis } \\
\text { radius }\end{array}$ & Perimeter & $\begin{array}{l}\text { Long axis } \\
\text { radius }\end{array}$ & $\begin{array}{l}\text { Short axis } \\
\text { radius }\end{array}$ & Perimeter \\
\hline 30d & $15.43 \pm 0.45^{*}$ & $4.33 \pm 0.03$ & $71.61 \pm 1.75$ & $14.12 \pm 0.59$ & $4.87 \pm 0.26^{*}$ & $67.57 \pm 2.59$ \\
40d & $14.93 \pm 0.44$ & $5.14 \pm 0.31$ & $71.46 \pm 2.50$ & $14.00 \pm 0.69$ & $6.52 \pm 0.15^{* *}$ & $70.86 \pm 3.03$ \\
50d & $13.88 \pm 0.28$ & $5.97 \pm 0.19$ & $69.14 \pm 0.74$ & $14.20 \pm 0.57$ & $5.72 \pm 0.19$ & $69.83 \pm 2.09$ \\
60d & $15.07 \pm 0.81$ & $6.33 \pm 0.38$ & $74.71 \pm 2.70$ & $14.40 \pm 0.65$ & $6.80 \pm 0.35$ & $73.10 \pm 2.83$ \\
\hline
\end{tabular}

Note: ** denotes significance at the 0.01 level; * denotes significance at the 0.05 level.

\section{Correlation analysis between various indexes and kernel moisture content}

The correlations between various indexes and kernel moisture content in the two varieties are shown in Table 2. Husk moisture content, cob moisture content, and ears shank length each had an extremely significantly positive correlation with kernel moisture content $(P<0.01)$, with the correlation coefficients ranging from 0.933 to 0.998 . Pericarp thickness had a significantly positive correlation with kernel moisture content $(P<0.05)$, and the correlation coefficients were 0.822 and 0.848 for the two varieties. In contrast, stomatal perimeter was negatively correlated with kernel moisture content $(P<0.01)$, and such a negative correlation was extremely significant for Zhengdan 958, with its correlation coefficient being -0.948 .

Table 2 - Correlations between indices and kernel moisture content in two varieties during the grain-filling stage

\begin{tabular}{llllll}
\hline Index & $\begin{array}{l}\text { Husk moisture } \\
\text { content }\end{array}$ & $\begin{array}{l}\text { Cob moisture } \\
\text { content }\end{array}$ & $\begin{array}{l}\text { Ears shank } \\
\text { length }\end{array}$ & $\begin{array}{l}\text { Pericarp } \\
\text { thickness }\end{array}$ & $\begin{array}{l}\text { Stomatal } \\
\text { perimeter }\end{array}$ \\
\hline Xianyu 335 & $0.933^{* *}$ & $0.990^{* *}$ & $0.995^{* *}$ & $0.822^{*}$ & -0.634 \\
Zhengdan 958 & $0.937^{* *}$ & $0.993^{* *}$ & $0.998^{* *}$ & $0.848^{*}$ & $-0.948^{* *}$ \\
\hline
\end{tabular}

Note: $* *$ denotes significance at the 0.01 level; * denotes significance at the 0.05 level. 
Vol. 4, No. 06; 2019

ISSN: $2456-8643$

\section{DISCUSSION}

Kernel moisture content varies among varieties and has a clear correlation with many traits. In this study, the kernel moisture content in Xianyu 335 was significantly lower than that in Zhengdan $958(P<0.05)$ within $20-60 \mathrm{~d}$ of the grain-filling stage. Kang et al (1978) found that husk moisture content had a significantly positive correlation with moisture content in at-harvest kernels and that husk weight had an extremely significantly positive correlation with moisture content in at-harvest kernels during the grain-filling stage (Kang et al, 1978; Kang and Zuber, 1989). In this study, the husk moisture contents within 40-60 d of the grain-filling stage in Xianxu 335 were all significantly lower than those in Zhengdan $958(P<0.05)$, and for both varieties, husk moisture content had a significantly positive correlation with the kernel moisture content $(P<0.01)$, consistent with previous findings. However, a study by Li et al (2016) showed that for the same varieties Xianyu 335 and Zhengdan 958, no significant difference existed in husk moisture content between the two varieties when cultivated in Beijing ( $\left.\mathrm{N} 39^{\circ}, \mathrm{E} 116^{\circ}\right)$ and in the Xinxiang City of Henan Province (N35 ${ }^{\circ}, \mathrm{E} 113^{\circ}$ ) ( $\mathrm{Li}$ et al, 2016), which the authors attributed to the different climatic conditions in the cultivation locations. In this study, the earstem moisture contents within $20 \sim 60 \mathrm{~d}$ of the grain-filling stage in Xianyu 335 were all significantly lower than those in Zhengdan $958(P<0.05)$, with a big difference between the two varieties. For both varieties, husk moisture content had a significantly positive correlation with kernel moisture content $(P<0.01)$, consistent with previous findings ( $\mathrm{Li}$ et al, 2016; Zhang et al, 2016).

There have been few studies on the correlation between the ears shank and kernel moisture content. Li et al (2016) found that ear-stem moisture content decreased slightly with an increasing number of days after pollination, but the changes were relatively stable, with a small reduction rate, such that no significant difference existed between Xianyu 335 and Zhengdan 958 and no correlation existed between the change in kernel moisture content and the change in earstem moisture content ( $\mathrm{Li}$ et al, 2016). In this study, the ear-stem length of Xianyu 335 was long and was significantly longer than that of Zhengdan 958 during the $40 \sim 60 \mathrm{~d}$ of the grain-filling stage $(P<0.05)$ and that ear-stem length had an extremely significantly positive correlation with kernel moisture content $(P<0.01)$ for both varieties. With a long ears shank, the husks distribution would be loose and would not tightly wrap the ear, which would contribute to the dehydration of the entire ear, thereby affecting the kernel moisture content. Similar results have been found in previous studies. For example, a loosening husk, shortening husk and few husk layers could each accelerate the dehydration in a corn ear (Troyer and Ambrose, 1971); when the husk is too long and too thick, a tighter-wrapped ear is more slowly dehydrated, and it is harder for the ear to grow and be harvested (Cross, 1985; Wang et al, 1987).

A corn kernel is a fruit; its outermost layer is the pericarp, which is tightly fused to the seed coat, and the pericarp and seed coat are, respectively, developed from the ovary wall and the inner integument (Dong et al, 2011). A study by Purdy et al. showed that the rate of kernel dehydration is affected by pericarp permeability and that good water permeability is conducive to kernel dehydration (Purdy and Crane, 1967). Zhang et al (2012) studied 10 inbred lines in Heilongjiang Province that had similar growth stages but large differences in the dehydration rate and found that the pericarp thickness had an extremely significantly negative correlation with the post-physiological-maturation dehydration rate (Zhang et al, 2012). The dehydration 


\section{International Journal of Agriculture, Environment and Bioresearch}

Vol. 4, No. 06; 2019

ISSN: 2456-8643

rate directly affects the kernel moisture content. In this study, pericarp thickness had a significantly positive correlation with kernel moisture content $(P<0.05)$. During the periods of within $20 \mathrm{~d}$ and of 40 60 d, the pericarp thickness of Xianyu 335 was lower than that of Zhengdan 958, which also provided evidence that pericarp thickness affected kernel dehydration.

Stomata are the channels for gas exchange between the inside and outside of the leaf. As the husk is a modified leaf, the morphology of its stomata would affect the discharge of water inside it and thus affect the husk moisture content. In this study, the stomata in the husk of Xianyu 335 were generally narrow and long within the first $40 \mathrm{~d}$ during the grain-filling stage, while those of Zhengdan 958 were short and ovular during the entire grain-filling stage. The stomatal perimeter of Xianyu 335 was significantly larger than that of Zhengdan $958(P<0.01)$ at $10 \mathrm{~d}$. Except for at $50 \mathrm{~d}$, the stomatal perimeters at all the other times in Xianyu 335 were greater than those in Zhengdan 958. Stomatal perimeter was negatively correlated with kernel moisture content. According to the small pore diffusion law, the rate of gas diffusion through the porous surface is not proportional to the pore area but is proportional to the pore perimeter. Accordingly, a large perimeter of the stomata in the husk would accelerate the loss of water from the husk and reduce the husk moisture content, thus reducing the kernel moisture content.

A comparison between Xianyu 335 and Zhengdan 958 showed that during the grain-filling stage, Xianyu 335 exhibited a low husk and cob moisture content, long ears shank, large perimeter of the stomata in the husk, and thin pericarp at the late grain-filling stage. Hence, Xianyu 335 had a fast kernel dehydration rate and a low kernel moisture content. There is a consensus about the effects of husk and cob moisture contents on dehydration rate and kernel moisture content. It is suggested that in the future selection and breeding of corn varieties with fast kernel dehydration and low moisture content during corn maturation and harvest, ears shank length, husk stomatal morphology and pericarp thickness could also be used as reference indices.

\section{ACKNOWLEDGEMENTS}

This project was supported by the grants from the 13th Five-Year National Key R\&D Program of China, the Special Foundation for Science and Technology Innovation in High-yield and Efficiency-enhancing Production (2017YFD0300505), the Science Foundation for Postdoctoral Research from Heilongjiang Province, China (LBH-Z13187), the National Key Technology Research and Development Program of the Ministry of Science and Technology of China (2013BAD07B01-05), and the Natural Science Foundation of Heilongjiang Province, China (C2016046). 


\section{International Journal of Agriculture, Environment and Bioresearch}

Vol. 4, No. 06; 2019

ISSN: $2456-8643$

\section{REFERENCE}

[1] Baute T, Haes A, Mcdonald I, Reid K, 2002. Agronomy guide for field crops. OMAFRA Publication 811, Ontario Ministry of Agriculture, Food and Rural Affairs (OMAFRA).

[2] Wang KR, Li SK, 2017. Analysis of influencing factors on kernel dehydration rate of maize hybrids. Sci Agri Sin 50: 2027-2035 (in Chinese)

[3] Crane PL, 1959. Factors associated with varietal differences in rate of field drying in corn. Agron. J 51: 318-320

[4] Purdy JD, Crane PL, 1967. Inheritance of drying rate in mature corn (Zea mays L.). Crop Sci 7: 294-297

[5] Kang MS, Zuber MS, Horrocks RD, 1978. An electronic probe for estimating ear moisture content of maize. Crop Sci 18: 1083-1084

[6] Kang MS, Zuber MS, 1989. Combining ability for grain moisture, husk moisture, and maturity in maize with yellow and white endosperms. Crop Sci 29: 689-692

[7] Li LL, Xie RZ, Fan PP, Lei XP, Wang KR, Hou P, Li SK, 2016. Study on dehydration in kernel between zhengdan958 and Xianyu335. J Maize Sci 24:57-61,71 (in Chinese)

[8] Zhang WJ, Wang YH, Wang KR, Zhao J, Zhao RL, Li SK, 2016. Grain dehydration rate of different maize varieties. Crops 1:76-81 (in Chinese)

[9] Troyer AF, Ambrose WB, 1971. Plant characteristics affecting field drying rate of ear corn. Crop Sci 11: 529-531

[10] Wang SH, Wang YS, Zhang YL, 1987. Discussing how to reduce the water content of maize grain to improve the quality of corn grain in Heilongjiang province. Heilongjiang Agri Sci 1: 42-45.(in Chinese)

[11] Cross HZ, 1985. A selection procedure for ear drying-rates in early maize. Euphytica 34: 409-418

[12] Dong YL, Huang CN, ZhaGP, Zhang JD, 2011. Research summary on pericarp thickness of maize. J Maize Sci 19: 146-147 (in Chinese)

[13] Zhang LG, Fan QJ, Chen XC, Li B, Zhang Y, Xiu LL, 2012. Correlation analysis on drydown rate and main agricultural traits in maize after physiological maturity. Heilongjiang Agri Sci 3:1-5 (in Chinese) 